\title{
Street homelessness and the architecture of citizenship
}

\author{
Martin Whiteford* \\ Bournemouth University
}

\begin{abstract}
The perception and experiences of homeless people in relation to the public spaces they occupy and identify as their own, and the corresponding struggle to assert and enact citizenship rights, remains an under-explored area of socio-cultural research. To help make sense of this neglect, I argue that citizenship - as a status and peformative act - is influenced and mediated by a series of complex and fluid interactions between physical, institutional and socio-political landscapes. This argument is developed with particular reference to an on-going PhD project that aims to illuminate the dynamic and complex ways in which rough sleepers draw on both context-specific experiential understandings and broader social processes in order to negotiate, embrace or challenge contemporary policy tropes and discursive strategies that position homeless people as degraded or shadow citizens. The paper concludes by arguing that any attempt to define more closely the relationship between street homelessness and contemporary citizenship must interrogate the meaning of citizenship empirically from the standpoint of homeless people and learn theoretically from these encounters.
\end{abstract}

Keywords: citizenship, exclusion, homelessness, welfare.

\section{Introduction}

Today, under the panoptical of New Labour's prescriptive moral agenda, citizenship has been recalibrated into a simple and crude binary. This civic stratification has resulted in a narrow, essentialist view of contemporary citizenship taking root which has as its crucial reference point the distinction between the socially embedded and economically purposeful 'active' citizen, and its antipode, the socially dislocated and welfare dependent 'passive' citizen. For this reason, there has been a significant renewal of interest in the location and characteristics of contemporary citizenship, particularly with regard to those communities or social groups who are perceived to be suffering the corrosive effects of deep exclusion (Carter, 2007). 
Transposed to mainstream public and policy discourses, the social exclusion of homeless people has become unerringly viewed as emblematic of passive citizenship. This suggests that, the exclusion of homeless people combines several interrelated dimensions, exclusion from the labour market, from social citizenship rights, ideological and housing exclusion (Stephenson, 2006). In these and other ways, homeless people have become positioned as part of a category of 'undeserving', 'dangerous' or, as the American sociologist David Matza (1990) comments, the 'disreputable' poor. Homeless people are thus conceived - discursively and symbolically - to exist on the margins in opposition to the values and everyday social relations of 'respectable' society. This involves, in turn, seeing homelessness as a shadow or degraded form of citizenship.

The major purpose of this paper is to critically address the relationship between street homelessness and contemporary citizenship. I employ the metaphor of 'architecture' to convey the discursive, institutional and ideological circuits which serve to channel homeless people into unequal social, economic and political relationships. Architecture as both a physical structure and ideological current also allows us to explore how formal and informal mechanisms regulate the quotidian practice of homeless people. In advancing this strategy, I argue that contemporary social policy interventions in respect of homelessness, while presented as compassionate and progressive are often complex and contradictory. My concern here is to argue that, far from enabling inclusive and pluralistic forms of citizenship, these shifts in public policy and political discourse aim to maximise the productivity of social space while reproducing the social values of the 'domiciled' majority. These assumptions are explored through direct empirical engagement with rough sleepers at a small voluntary daycentre in Dorchester. My approach, therefore, suggests that theorising about the relationship between homelessness and citizenship should - as an intellectual and moral precondition - draw on the local context and on the perspectives of homeless people while, simultaneously and significantly, explaining how the actions and perceptions of homeless people are shaped by socio-cultural processes, which extend both 'down' into street culture and 'up' into social policy and the public sphere.

Developing this line of analysis, I will address four key themes: (i) the dichotomy between 'active' and 'passive' citizenship; (ii) community governance in respect of homeless people; (iii) and the politics of exclusion. Underlying these four themes, and running through the discussion as a whole, are two further key issues, namely, the nature and boundaries of the homeless experience, and debates concerning the relationship between contemporary welfare reform and homelessness.

\section{The Dorchester Study}

Before entering into a substantive analysis it is necessary to first briefly place this - albeit modest contribution - within the wider context of an evolving PhD research project that investigates how street homelessness and contemporary citizenship are linked through the logic of standpoint theory (Harding, 1983). This research, based on ethnographic fieldwork, explores how notions of social exclusion and passive citizenship get reworked on the street, both in what people say and what people do (Gowan, 2002). It also sets out to investigate how homelessness as the iconic subject of social exclusion has become a key arena within the context of contemporary New Labour policy discourse, one which fuses the themes of neo-liberalism and neo-communitarianism, and a corresponding return to 
punishment, surveillance, and exclusion as the dominant modes of social cohesion and control (Fyfe, 2005).

My principle research site is the Hub Project for rough sleepers in Dorchester, a place of contemporary affluence as well as small pockets of literal and visible street homelessness. In Dorchester, as with other small urban towns with a large rural hinterland, homelessness has been a recurrent if largely overlooked social reality. Historically, homeless people and wayfarers (men of the road) have been drawn to the town by virtue of its symbiotic relationship with Dorchester Prison, its proximity to the Pilsdon Community, Hilfield Friary and the Dorset coast. As such Dorchester was - and to a significant extent remains - a key nodal point in homeless migration strategies (Whiteford, 2008).

While historically such tendencies have been underlain by the wider homeless migratory circuit, the contemporary response to rough sleeping in Dorchester have been stimulated by an increasing appreciation of the scarcity of social housing and insufficient support services for a small but significant community of homeless people. Alongside this, a renewed focus on the policy and strategic approaches needed to tackle homelessness and social exclusion resulted in new duties for local authorities to produce homelessness strategies (Van Doorn and Kain, 2007). At the theoretical level, Newman (2002) has argued that such developments should be seen within the context of New Labour's drive to re-imagine the relationship between the state and citizen, with the state's role moving from provider of (welfare) services, to that of facilitator. Under this model, community participation and localism are invoked in order that communities and individuals take greater control and responsibility in their own governance.

The Hub Project was originally conceived in response to the recognition that local voluntary and statutory agency support for homeless people in rural Dorset was inadequate. Today, the Hub Project operates under the auspices of Dorchester Poverty Action, and is essentially a 'survivalist' agency providing hot food and drinks, clothes, blankets and showers. Additionally, the Hub Project also provides limited but direct access to a nurse practitioner, a drug and alcohol prevention worker and a Shelter housing specialist through an appointment based system. These services, taken together, reflect the Hub's commitment to addressing the health and housing needs of homeless people by developing strategies that, however partially and imperfectly, have the potential to contribute towards breaking the cycles of poor health and housing exclusion.

In attempting to produce local spaces of welfare, there is a strong and intractable argument that the very existence of the Hub Project has served to attract in-migrant homeless people. It is within this context, and against this changing social policy terrain, increasing evidence exists to suggest that homeless people have 'migrated' to Dorchester in an effort to access basic support services. The following quotes describe the interconnections between the prevailing social care landscape and the local policy process:

In Dorchester, we have been accused of attracting people from far and wide. This may have an element of truth, but if there were similar day facilities in neighbouring towns (like Weymouth and Blandford etc) then people would not migrate to the Hub for the support and help they need (Barker, Broome, Caullified, 2007).

Support for the view, from within as well as outside the Hub Project, as to its ability to effectively cope with the increased demands placed on the service has given rise to a significant realignment of its relationship to the wider community. Such concerns seem 
mainly to be associated with the notion that the highly visible presence of people sleeping rough on the streets of Dorchester symbolises a challenge to the locally hegemonic 'spatial code' as well as to what Halfacree has described as the 'spatiality of the imagination' (1996:45).

Underlying these developments, a discourse of 'local knowledge' has been articulated by rough sleepers and wayfarers in my research emphasising the importance of the link between spatial context and social networks in shaping the choices and constraints faced by homeless people as they negotiate access to social welfare. Hence, this is to draw attention to the argument that the Hub's existence and, pivotally, its geographic setting demonstrate how the geographic unevenness of local support services for homeless people is deeply entwined with the highly mobile character of the single homeless population (Higate, 2000).

Not surprisingly, this emphasis on the migratory strategies employed by homeless people has become a crucial rallying point in the wider politics of community and contractual governance (Rose, 2001). The issue of on street homelessness, in this context, opens up a path towards gaining a critical appreciation of New Labour's communitarian ethos and its drive to identify 'community' as both the location and processes of governance (Flint and Nixon, 2006: 941).

There are parallels to be made here in relation to the work of Mitchell (2001) and Katz (2001) whose useful analyses of the increasingly controlled and surveilled nature of public environments intersects with a detailed consideration of the various forms of socio-cultural policing of the performances and practices of homeless people. This is useful in thinking more broadly about the way in which homeless people are routinely excluded from prevailing notions of 'community'. It also points to the ways in which 'responsible communities' target both the involuntary status of being homeless and the supposed failure of homeless people to conform to the normative standards of a more 'active' and self-disciplined conception of citizenship (Anker, 2008).

\section{Passive and Active Citizenship}

In recent years, political discourse and academic inquiry has emphasised the distinction between 'active' citizenship and its cognate 'passive' citizenship (Levitas, 2005; Tonkens and Van Doorn, 2001). The cultural logic of this civic stratification of citizenship leads inexorably towards an overarching focus on responsibility and community processes which privilege individual duty and autonomy, communitarianism and a neighbourhood levelfocus on the social and cultural as well as economic dynamics of exclusion. Corresponding to this process, we can see the progressive erosion of the welfare entitlement of citizenship in favour of a moral authoritarianism that has sought to portray individual fecklessness rather than government policy as the causal factor in an increasingly hostile, suspicious, antagonistic and unequal society. Here, neo-liberalism has rendered obsolete the notion that certain welfare provisions are not only impenetrable to commodification but also enduring. Today, citizenship is a key term for New Labour and draws increasingly on the lexicon of obligations rather than rights (Roche, 1992). To be sure, New Labour has made it clear that it is consistently willing to invoke the language of citizenship in order to inform and justify its welfare policy. Integral to such thinking has been the promotion of a particular type of moral community in which citizens earn access to their social rights 
through a combination of hard work, responsible behaviour and personal contributions (Dwyer, 2002: 274).

Under the prevailing neo-liberal order, with its turn away from emancipatory and egalitarian goals associated with traditional welfare paternalism, rough sleeping has become the iconic subject of social exclusion. The moral architecture underpinning this new social policy terrain and its accompanying discourse can be seen as a vehicle for two concepts at the centre of the New Labour project. On the one side, a social inclusion framework that endorses the extension of affordable housing, education and employment opportunities, as well as greater tolerance for diverse living arrangements. But equally, it can be used to endorse policies that require various forms of social participation as part of 'mutual obligation' between individuals and society. Overall, then, this has resulted in greater conditionality, reduction or removal of services and opportunities, rather than their extension.

The effect of this ideological shift has given rise to the discursive positioning of homeless people vis-à-vis societal norms as 'other' or 'deviant'. Understanding this, Takahashi (1996) has argued that contemporary representations of homeless people are defined by perceptions regarding their productivity, degree of dangerousness and personal culpability for episodes of homelessness. In light of these developments, Mitchell (2001) has argued that we have moved from an earlier position of 'malign neglect' of homeless people towards a more obviously punitive urban regime. The overall effect of this drive is that in terms of intellectual attraction and public support 'social inclusion' has been steadily stripped of its transformative power. All of this shows that the vocabulary of citizenship, presented in terms of inclusion and exclusion, is increasingly deployed as an instrument for the responsibilsation of homeless people (Phelan and Norris, 2008). Given this, we can begin to identify the unfolding of a silent but powerful manoeuvre in which there is a deliberate attempt to exclude certain groups, in order to readmit them (or not) to the social fold on special, punitive terms (Calder, 2003).

\section{Community Governance}

Displaced people represent a danger to social order. Being unattached and transient, homeless people are seen as a threat to social order (Stephenson, 2006).

In Dorchester, as with many support services for homeless people serving rural environments, the Hub Project stands uneasily between containing the perception of a homelessness 'problem' and the wider 'place image' of the town which is predicated on a sense of gentility, entrepreneurial spirit and, above all, its desirability as a tourist destination and gateway to the imaginary world of Wessex. As such, the issue of street homelessness in Dorchester provides a useful example from which to seek to understand and critique the way in which a diverse constellation of forces have mobilised in order to reproduce boundaries of inclusion and exclusion.

At the centre of this new spirit there has been a determined effort to characterise homeless people, socially and geographically, as 'outsiders'. In this regard, Rahimian et al. (1994) have described how contemporary representations and perceptions of homeless migrants are used as a common political strategy by local authorities attempting to avoid obligations to provide support to homeless individuals on the basis of their transiency. However, in Dorchester the effect is as much economic as it is symbolic. 
In a delicately crafted analysis, Robinson has pointed out that the invisibility of rural homelessness in local and national political discourses has had a powerful and persuasive influence in shaping the social construction of homelessness among rural residents (2006:97) Recognising this, I want to suggest that in this context rough sleepers in Dorchester are perceived to represent a significant transgression of socio-spatial expectations and, as such, reifies the distinction between where homelessness is in, or out, of place (Cloke et al., 2001).

On a more immediate level, I now wish to briefly consider the central and defining role that the local media has undertaken in relation to the perceived visibility of street homelessness in Dorchester and its immediate environs. A careful reading of the Dorset Echo suggests that it has attained a key strategic position in framing discussions and debates about the Hub Project, rough sleepers and Dorchester's self-image and community ethos. Insightfully, Zufferey (2006) has noted that elsewhere that media representations of homelessness and 'homeless people' inform public discourses and practical responses, influencing the social and physical space people experiencing homelessness can occupy. Thus the Dorset Echo has assumed 'vehicular power' in mobilising public support for the socially pernicious charge that the sight of people sleeping rough in Dorchester tarnishes the character of town and contributes to a broader process of degradation and alienation. What is striking is that this perspective echoes the rhetoric of New Labour by framing the social exclusion of homelessness within a discourse that shapes public opinion along two thematic lines. On the one hand, homeless people in Dorchester have been characterised as representing a threat to social order, and homelessness as a problem of social integration. On the other hand, homeless people in Dorchester are portrayed as victims. In this representation, their role as active agents is purposefully ignored or discounted. These two contrasting representations - homeless people as, alternately, both threat and victim function to manage public opinion and to maintain support for social policy interventions.

To this end, it is important to recognise that this kind of moral discourse is by no means unique to events in Dorchester. In a similar fashion, the imagery of pollution, disorder and incivility might be read as an ideological process that Sibley (1995) terms the "purification of space', a process enacted via the identification and removal of unsightly people, which is as applicable to rough sleepers as it is to Roma Gypsies. What is equally important to understand is the way in which these discursive strategies, in turn, serve to ensure that the everyday social relations between homeless people and the 'settled' community are increasingly shaped by conflict, antagonism and avoidance.

\section{The Politics of Behaviour}

Far from being free, open or 'unrestricted' public space is in fact highly controlled space. It is layered with rules, regulations and bylaws and practices which govern its occupation and use. Some of these rules are explicit and obvious, but most are well hidden. Many are revealed or evoked only be the absence and exclusion of those who might transgress them (Winford, 2006:55).

By seeking to redefine popular understandings of contemporary 'social welfare' New Labour in its apparent compassion and enthusiasm to provide exit routes from homelessness, has pursued a complex and contradictory policy agenda. It is in this respect that homelessness has become a site of symbolic struggle in which conventional (and 
idealised) notions of the 'inclusive society' are buttressed by a corresponding regime of deterrence, denial and discipline (Fitzpatrick and Jones, 2005). What this suggests is that the governance of homelessness involves the imposition of surveillance and programmes of social control. Thus, the particular complexities of the homeless experience are now ensnared with a wider attack on incivility in everyday life and a perceived epidemic of street crime through the expression and elaboration of increasingly coercive legal mechanisms.

When transferred to the realm of social policy intervention, the idea of strong, cohesive communities has given rise to a series of instruments and quasi-legal sanctions which, putatively and purposefully, aim to tackle anti-social behaviour and reduce crime (Nixon et. 2008). In terms of outcome, the use of dispersal orders and curfew orders has led to the emergence of aggressive policing tactics around public and marginal spaces traditionally associated with, and used by, homeless people.

At this point, we should also note that this unfolding logic of increased regulation, surveillance and punishment is sedimented within a dominant mode of social control. It is from within this environment that current interpretations of anti-social behaviour draw upon negative stereotyping and rhetorical narratives that undermine the social status of marginalised groups (Jacobs, 2006:12). As a political and moral project, the notion of 'antisocial behaviour' is open to the accusation that it is both authoritarian and persecutory in its nature and impact.

Embracing the shift towards community governance through the surveillance of behaviour, Dorset Police have focused on issuing rough sleepers with 'dispersal orders'. These legal and ideological devices are geared to managing groups perceived as marginal and troublesome. In effect the deployment of dispersal orders further constrict the rapidly diminishing public spaces available to homeless people, but also serve to overtly criminalise poverty and homelessness.

Homeless people in Dorchester, sited at the social and economic margins, have no choice but to occupy public space. Understanding this, Blomley (1994) has pointed out the urban environment both shapes, and is shaped by, all those who inhabit it, including homeless people. However, efforts to both shape and change the physical landscape of Dorchester has resulted in rough sleepers being deemed problematic on the grounds that homelessness is 'out-of-place' because it partly stands in opposition to normal rules of propriety (Cloke, 2003). This repressive turn towards the language and use of anti-social behaviour orders exists to provide a degree of symbolic reassurance to 'respectable' society that effective action is being taken against crime and incivility and, therefore, has a disciplinary effect on the behaviour of rough sleepers.

As part of this process Dorset Police have issued orders to disperse under Section 30 of the Anti Social Behaviour Act, and confiscated alcohol from homeless people who occupy both 'prime' and 'marginal' spaces within the town centre and its neighbouring streets (Dorset Police, 2008). Add to this, anecdotal evidence that suggests rough sleepers are routinely woken by police officers and on many occasions, searched as well, moved on from begging sites, given warnings about perceived behaviour and threatened with arrest, we can quite clearly see the regulation of the quotidian practices of rough sleepers within the town.

The governance of anti-social behaviour in Dorchester has fallen disproportionately on rough sleepers. The ubiquitous surveillance of homeless people demonstrates that the imposition of curfews and dispersal orders can prevent homeless people from seeking help 
p. 95. Street homelessness and the architecture of citizenship

from services they need, such as medical care, drug treatment and support agencies (Johnsen and Fitzpatrick 2007). The resultant landscape reflects and reveals not only those with power but, perhaps more crucially, has served to limit access to the Hub Project, thus distancing the multiple support needs of people who have experienced or are experiencing acute social exclusion from services that attempt to address specific wants and needs that would otherwise go unmet.

As Tony explains, this is not however a process that goes unchallenged:

We occupied the [Hub] forecourt last night. There were four of us and two of the dogs. The Police came and tried to move us on. We told them that this was private property and that we were allowed to sleep out because we use this service everyday.

On street homelessness may have disappeared from the 'prime spaces' of Dorchester, but it will inevitably resurface because as Coleman has perceptively remarked 'the city is, and always has been, constituted as a contest over space - over its production, representation and regulation; over who is authorised to be in it and who is kept out; over what constitutes an unpolluted space and what constitutes transgression of space' (2005: 143).

Through this prism we can discern the homeless experience as a struggle against sociospatial marginalisation. This is a crucial point because it proposes that rough sleepers in Dorchester are engaged in spatial struggles that serve to resist preconceptions about their identity and against processes and spaces of increased regulation, surveillance and punishment. What seems especially important is the recognition that homeless people are constantly embroiled in power struggles which serve to make and remake the urban landscape and experience. This gives cohesion and a unifying perspective to the fact that while criminal justice, policing, housing and other social welfare policies fail to address the critical and troubling dynamics associated with social exclusion, homeless people themselves are active in their own situations, continue to make decisions and take action (Pain and Francis, 2004). Such an analysis, I believe, has significant implications for how we might productively go about disentangling the relationship between homelessness, social exclusion and citizenship.

\section{Discussion}

In the preceding discussion I mapped out the discursive and institutional architecture that constrain and foreshorten the ability of homeless people to enact citizenship claims. In so doing I have attempted to show that within the context of contemporary New Labour policy discourse, marginal and reviled social groups such as the homeless people are portrayed as existing outside the norms of the dominant culture, a threat to the social order and, therefore, to the power base of established groups (Powell, 2007).

Yet such an analysis is, ultimately, incomplete. In trying to understand how notions of social exclusion and passive citizenship get reworked on the street, both in what people say and what people do, it is both imperative and urgent that critically engaged social research is driven by an ethical and empirical commitment to giving 'voice' to homeless people. This entails recognising that to ignore or overlook the standpoint of homeless people in research leaves a major gap in our understanding of the less visible structures and 
p. 96. Street homelessness and the architecture of citizenship

processes, which engender and sustain 'life on the streets' and repeat episodes of homelessness.

At this point, I want to suggest that homeless people are both aware of their degraded position in society and have a broader sense of the external issues exerted on them (Parker and Fopp, 2004). More interestingly, however, my experience of undertaking ethnographic fieldwork shows that homeless people negotiate discursive strategies and material circumstances which position homeless people as 'passive' citizens and, in so doing, challenge dominant discourses and social practices. To accomplish this task, I offer three vignettes that serve to illustrate the often contradictory and context specific ways in which homeless people reproduce dominant, oppositional and mediated discourses:

In the first example, Richard, an entrenched rough sleeper suggests that 'life on the street' is a form of social inclusion, rather than social exclusion by highlighting themes of 'community' and 'independence'.

I have been offered a flat that I will probably accept, although I intend using it for storage. Then I will go back on the street or on-site (temporary and illegal travellers encampments) Why would I want to struggle with a TV licence, utilities and boredom? It's better to be with friends, people who don't judge and just accept you.

By contrast, Paul, a street musician while recognising his own degraded position embraces 'received and conventional wisdom' to denounce others.

Housing aren't prepared to take a homelessness application because I am not a junkie, piss-head or bloody foreigner. I don't scrounge. I'm prepared to work, and work hard, unlike most of the homeless wasters.

While not overtly acquiescing with dominant representations, Eric, 50, a skilled tradesman who became homeless upon being deported from the Channel Islands having been unable to secure employment contrasts the demeaning status evoked by being homeless with the culturally powerfully valorisation of 'paid employment':

With the new flat soon and catering college, it's a new start and chance to make a real change. I want to work and not to feel stigmatised because I am homeless and claiming benefits. I suppose I want to feel a sense of self-respect and social worth.

These examples make plain that people who are homeless are not immune from the ideologies that demonise, pathologise and penalise them and in policies, programmes and service delivery seek to normalise (Fopp, 2007). This is to be mindful of the fact that discursive practices are important because they contain moral judgements which, in turn, may justify action or inaction. They are also important because they help to construct the actual experience of being 'homeless' or 'socially excluded'.

\section{Conclusion}

The architecture of street homelessness in Dorchester reveals that New Labour's promissory note to eradicate the spectre of rough sleeping from both urban landscapes and public consciousness has oscillated in the past decade from a creative vision which 
was, ostensibly at least, prefaced on offering a more permanent solution to the problems of homelessness to its current, more punitive concern with regulating public space and individual behaviour within the calculus of the new politics of conduct. However, viewed from a setting such as Dorchester where access to well-resourced, imaginative and experimental substance misuse support programmes, mental health services and education, training, volunteering and employment opportunities is severely rationed or completely absent, the prospect of exiting homelessness and reconnecting with mainstream society is fundamentally at odds with New Labour's professed commitment to the 'social excluded'.

All of this shows that the distinction between active citizenship and passive citizenship is increasingly deployed as an instrument for the responsibilisation of homeless people. In such a context, we need to highlight the fact that dividing contemporary citizenship into two disparate and seemingly irreconcilable camps, both as an analytical category and organising tool, has very little resonance in the everyday geographies of homelessness. Binary oppositional thinking such as this is obviously mechanical rather than dialectical, suggesting discrete entities while in reality homeless people's experiences of, and responses to, becoming homeless resist such crude and reductive schemas.

Evidence from Dorchester suggests that we need to be mindful of the fact that antisocial behaviour strategies and the all powerful and persuasive shibboleth of community governance targets the most disadvantaged and vulnerable and, ultimately, serves to deflect from a sustained focus upon the responsibilities of wider society for tackling homelessness and the most extreme forms of social exclusion. Building on this insight, we also need to recognise that the de facto criminalisation of homelessness through the unfolding logic of spatial exclusion and identity purification illustrates that there are deep rooted and intractable obstacles to enabling homeless people to become full and active citizens. Only by contesting this exclusion - by establishing as Hannah Arenndt (1958) puts it, 'a place in the world which makes...action effective' - can homeless people challenge as citizens these powerful and pervasive circuits of injustice.

\section{Notes}

1. This article is a revised version of a conference paper given at the Interdisciplinary Centre for Citizenship and Democracy, University of Southampton, December 52007.

2. Following Mitchell Duneier's (2001) appeal to the ethnographic community, I have chosen to disclose the place and names of the people I have written about (unless requested to do otherwise) because I believe that such a commitment increases accountability.

3. I would like to thank Bob Matthews, the manager of the Hub Project, and volunteers and service users who have made a direct contribution to this paper.

*Correspondence Address: Martin Whiteford, School of Health and Social Care, Bournemouth University, R503, Royal London House, Christchurch Road, BH1 3LT, UK. Email: mwhiteford@bournemouth.ac.uk 
p. 98. Street homelessness and the architecture of citizenship

\section{References}

Anker, J. (2008) Organising Homeless People: Exploring the Emergence of a User Organisation in Denmark. Critical Social Policy, 28, 1, 27 - 50.

Arenndt, H. (1958) The Human Condition. Chicago: Chicago University Press.

Blomley, N. (1994) Mobility, Empowerment and the Rights Revolution. Political Geography, $13,5,407-22$.

Calder, G. (2003) Communitarianism and New Labour. The Electronic Journal: Social Issues 2, 1. Available at http://www.whb.co.uk/socialissues/vol2gc

Carter, M. (2007) Towards an ESRC Research Programme on Multiple Exclusion Homelessness: Consultation Report for the Homelessness Research Forum. Available at http://www.homelessness.org.uk

Cloke, P., Milbourne, P. and Widdowfield, R. (2001) Interconnecting Housing, Homelessness and Rurality: Evidence from Local Authority Homelessness Officers in England and Wales. Journal of Rural Studies, 17, 99 - 111.

Cloke, P. (2003) The Complex Mobilities of Homeless People in Rural England. Geoforum, 34, 1, 21-35.

Coleman, R. (2005) Surveillance in the City: Primary Definition and Urban Spatial Order. Crime Media Culture, 1, 2, 131 - 148.

Barker, M., Broome, A. and Cullified, J. (2007) The Hub, yes we have made mistakes but please be tolerant. Dorset Echo, 31 May 2007. Available at http://www.dorsetecho.co.uk.

Dorset Police (2008) Freedom of Information Request. Personal Email, 11 January 2008.

Duneier, M. (2001) Sidewalk. New York, Farrar, Straus and Giroux.

Dwyer, P. (2002) Making Sense of Social Citizenship: Some User Views on Welfare Rights and Responsibilities. Critical Social Policy, 2, 2, 273-299.

Fitzpatrick, S. and Jones, A. (2005) Pursuing Social Justice or Social Cohesion? Coercion in Street Homelessness Policies in England. Journal of Social Policy, 34, 3, 389-406

Flint, J. and Nixon, J. (2006) Governing Neighbours: Anti-social Behaviour Orders and New Forms of Regulating Conduct in the UK. Urban Studies, 43, 5/6, 939 -955.

Fopp, R. (2007) Beginning our Research from the Standpoint of the Homeless: Theory, Practice and Policy. Paper presented at the Inaugural National Homeless Research Seminar $12^{\text {th }}-13^{\text {th }}$ April, University of Melbourne.

Fopp, R. and Parker, S. (2004) The Voice of People Who Are Homelessness: Some Consideration. Parity, 17, 9, 13-14.

Fyfe, N. (2005) Making Space for Neo-Communitarianism? The Third Sector, State and Civil Society in the UK. Antipode, 37, 3, 536 - 557.

Gowan, T. (2002) The Exclusion/Punishment Nexus: How Imprisonment Leads to Homelessness and Back Again, In: Ethnography, 3, 4, 500-535.

Halfacree, K. (1996) Out of Place in the Country: Travellers and the 'Rural Idyll'. Antipode, $28,1,42-71$.

Harding, S. (1993) After the Neutrality Ideal: Science, Politics and Strong Objectivity. Social Research, 59, 3, 567 - 587.

Higate, P.R. (2000) Tough bodies and Rough Sleeping: Embodying Homelessness Amongst Ex-Servicemen. Housing, Theory and Society, 17, 3, 97-108.

Jacobs, K. (2006) Neo-Liberal Ideology and the 'Problem' of Anti-Social Behaviour. Parity, $19,1,12-14$.

Johnsen, S. and Fitzpatrick, S. (2007) The Impact of Enforcement on Street Users in England. Bristol: The Policy Press. 
p. 99. Street homelessness and the architecture of citizenship

Johnsen, S., Cloke, P. and May, J. (2005) Transitory Spaces of Care: Serving Homeless People on the Street. Health and Place, 11, 323-336.

Katz, C. (2001) Hiding the Target: Social Reproduction in the Privatised Urban Environment, in C. Minca (Ed) 93 - 112 Postmodern Geography: Theory and Praxis. Oxford: Blackwell Publishers.

Kain, M. and Van Doorn, A. (2007) Homeless Sector Culture, in M. Seal (Ed) Understanding and Responding to Homeless Experiences, Identities and Cultures. Lyme Regis: Russell House Publishing.

Lake, R.W. and Newman, K. (2003) Differential Citizenship in the Shadow State. GeoJournal, 58, 109 - 120.

Levitas, R. (2005) The Inclusive Society? Social Exclusion and New Labour. Basingstoke: Palgrave.

Matza, D. (1990) Delinquency and Drift New York, Transaction Publishers.

Mitchell, D. (2001) The Devil's Arm: Points of Passage, Networks of Violence and the Political Economy of Landscape. New Formations, 43, $44-60$.

Mitchell, D. (2001) Postmodern Geographical Praxis? The Postmodern Impulse and the War Against Homeless People, in the Post-Justice City, in C. Minca (Ed) 57 - 92 Postmodern. Geography: Theory and Praxis. Oxford, Blackwell Publishers.

Newman, J. (2002) Changing Governance, Changing Equality? New Labour and the Modernisation of Public Services. Public Money and Management, 22, 1, 7 - 14.

Nixon, J., Hodge, N., Parr, S., Willis, B. and Hunter, C. (2008) Anti-Social Behaviour and Disability in the UK. People, Place and Policy Online, 2, 1, $37-47$.

Pain, R. and Francis, P. (2004) Living with Crime: Spaces of Risk for Homeless People. Children's Geographies, 2, 1, 95 - 110.

Pawson, H. and Davidson, E. (2008) Radically Divergent? Homelessness Policy and Practice in Post-Devolution Scotland. European Journal of Housing Policy, 8, 1, 39 60.

Phelan, E. and Norris, M. (2008) Neo-Corporatist Governance of Homeless Services in Dublin: Reconceptualisation, Incorporation and Exclusion. Critical Social Policy, 28, 1, $51-73$.

Powell, R. (2007) Civilising Offensives and Ambivalence: The Case of British Gypsies. People, Place and Policy Online. Available at http://www.extra.shu.ac.uk

Rahimian, A., Wolch, J. and Koegel, P. (1994) A Model of Homeless Migration: Homeless Men In Skid Row, Los Angeles. Environment and Planning A, 24, 1317 - 1336.

Robinson, D. (2006) The Hidden and Neglected Experiences of Homelessness in Rural England, in: Milbourne, P. and Cloke, P. (Eds) 97 - 120 International Perspectives on Rural Homelessness. London: Routledge.

Roche, M. (1992) Rethinking Citizenship: Welfare, Ideology and Change in Modern Society. Cambridge, Polity Press.

Rose, N. (2001) Community, Citizenship and the Third Way, in: D, Merydyth and J. Minson (Eds) Citizenship and Cultural Policy, 1 - 17. London: Sage.

Sibley, D. (1995) Geographies of Exclusion. London: Routledge.

Stephenson, S. (2006) Crossing the Line: Vagrancy, Homelessness and Social Displacement in Russia. London: Ashgate.

Takahashi, L.M. (1996) A Decade of Understanding Homelessness in the USA: from Characterisation to Representation. Progress in Human Geography, 20, 3, 291 310. 
p. 100. Street homelessness and the architecture of citizenship

Tonkens, E. and Van Doorn, L. (2001) Turning Rough Sleepers into Responsible Citizens: Third Way Policies on Homelessness in England and the Netherlands. Renewal, 9, 2, $142-151$.

Whiteford, M. (2008) Who are the Wayfarers (And Why are They Still Here)? Unpublished Manuscript, Bournemouth

Winford, S. (2006) A New (Legal) Threat to Public Space: The Rise and Rise of the ASBO. Parity, 19, 1, 55 - 58.

Zufferey, C. (2006) Who Controls the Public Space? The Print Media, Homelessness and Social Work in Australian Cities. Parity, 19, 1, 21 - 23. 